Knowledge level among group III participants is significantly higher than group II participants $(p<0.001)$.

Conclusion Group I students are least aware about the epidemiology and aetiology of cervical cancer, HPV and HPV vaccines. Group II student are unaware about HPV vaccines pricing, manufacturer and dosing schedule. Group III students had significantly more knowledge in almost all parts of questionnaire. Therefore, we should stress in above groups in the area where they are lacking because in future they are going to play a role of physician.

\section{P5.053 CHALLENGES IN DEVELOPING SOCIAL MEDIA AND WEB-BASED COMMUNICATION TOOLS FOR HIV-AIDS AND STI INTERVENTION FOR MSM AND TRANSGENDER COMMUNITIES IN INDONESIA, MALAYSIA, PHILIPPINES AND TIMOR LESTE}

doi:10.1136/sextrans-2013-051184.1097

\section{R D Nasution. SatuDunia, Jakarta, Indonesia}

Background The ISEAN-Hivos Program is a Global Fund HIVCommunity Systems Strengthening Program focused on MSMs and Transgenders (TG). It aims to provide information and capacity building to local MSM and TG communities in four countries, Indonesia, Malaysia, Philippines and Timor Leste. The Program acknowledges the importance of web-based and social media interventions to access the hidden and difficult to reach populations of MSMs and TGs. Baseline studies have shown the MSM and TGs in the region have turned to online media to socialise and network. This ironically increases their vulnerability to HIV-AIDS and STI due to easier "sexual networking".

Methods Two social networks, PlaySafe and Peer Support network are created to raise awareness about HIV-AIDS and STI to MSM and TG, and People living with HIV/AIDS. A web-base BCC online is developed to provide information and 'lectures' through videos, including: Basic Information on HIV-AIDS, MSM and TG Human Rights and Access to HIV and STI Services. The knowledge hub is developed to open access to papers, studies, advocacy works and references for public.

Results Concerns over the registration system and client coding were noted, as well as the mechanism for which site users are to identify themselves whether they are MSM or TG Suggestions were also made to use local images in the videos for local communities. Comments on the websites functionalities include creating links to other websites, improving internal consistencies and process of providing feedback on the online post-tests.

Conclusions Creating on-line interventions are indeed essential in reaching out to hidden populations like MSM and TGs. Development of these tools needs to be appropriated and aligned with campaign and communication strategy, learning strategy, networking strategy; and the on-line behaviour of specific target MSM and TGs communities in each country, while maintaining the regional perspectives.

\section{P5.054 ATTITUDE AND PERCEPTIONS OF PEOPLE WHO INJECT DRUGS (PWID) TOWARDS NON-TRADITIONAL SEXUAL ORIENTATION, BARNAUL, RUSSIA FEDERATION}

doi:10.1136/sextrans-2013-051184.1098

LL Zohrabyan, ${ }^{2} \mathrm{~L}$ Sultanov, ${ }^{3} \mathrm{E}$ Demianenko, ${ }^{4} \mathrm{~N}$ Vagaitseva, ${ }^{1} \mathrm{~J}$ Malkin, ${ }^{5} \mathrm{C}$ Garcia Moreno, ${ }^{6}$ Toskin. 'UNAIDS, Moscow, Russian Federation; ${ }^{2}$ Center for AIDS and Infectious Disease Prevention of Altay Krai, Barnaul, Russian Federation; ${ }^{3}$ Altay Kray Public Organization "AntiAIDS-Siberia", Barbaul, Russian Federation; "Altay Kray Public Organization "AntiAIDS-Siberia", Barnaul, Russian Federation; 'Department of Reproductive Health \& Research (RHR) World Health Organization Geneva, Geneva, Switzerland; ${ }^{6}$ Department of Reproductive Health \& Research (RHR) World Health Organization, Geneva, Switzerland
Background PWID engaged in unconventional sexual behaviour run the greater risk of becoming HIV infected due to multiple sexual and injecting risks. We sought to test the sexual health indicators (SHI) developed by UNAIDS/WHO and understand the impact of attitude on risk behaviour of PWID.

Method RDS was used in a cross sectional survey to recruit 500 PWID in August-October 2012 in Barnaul, Russia. One of the composite SHIs defined as "Conformity with traditional social norms concerning gender and sexuality among men and women 15+" included a question "Homosexuality is normal diversity of sexuality". Respondents should either "Agree" or "Disagree" with the above statement. RDSAT was used to calculated point estimates.

Results Response rate was $94.2 \%$. More than a half of all participants reported incarceration history $(60.3 \%, 95 \%$ CI 55.2, 65.4) and coverage by prevention programmes $(64.2 \%$, 95\% CI 58.3, 69.7). Majority $(90.7 \%, 95 \%$ CI 85.4, 90.4) disagreed with statement: 96.0\% (95\% CI 91.4.98.7) of men and $79.4 \%(95 \%$ CI 67.5 .90 .20$)$ of women. Young female PWID (<30 years) had highest proportion of negative attitude $(94.4 \%, 95 \%$ CI 89.1, 99.1) among all age groups. Positive attitude among PWID who reported no incarceration was $13.9 \%(95 \%$ CI $7.5,21.9)$ and who had been incarcerated $2.9 \%(95 \%$ CI $0.8,5.1) .82 .6 \%(95 \%$ CI $72.1,92.7)$ of women at 30-39 had negative attitude. $66.3 \%$ (95\% CI 51.4, 77.7) of female PWID who disagreed did not use condom at last sexual contact while those who agreed - $17.5 \%$ (95\% CI 5.8, 31.4). In comparison with women $2.9 \%$ (95\% CI0.1, 8.1) of men PWID who agreed did not use condom.

Conclusions History of incarceration correlates with negative attitude towards non-traditional sexual orientation as well as condom use by PWID. Further research is necessary to understand social determents and behavioural factors and develop adequate interventions.

\section{P5.055 BUILDING A NATIONAL COALITION FOR SEXUAL HEALTH IN THE US: OVERVIEW OF A PARTICIPATORY APPROACH WITH KEY STAKEHOLDERS}

doi:10.1136/sextrans-2013-051184.1099

P S Loosier, ${ }^{2} \mathrm{~A}$ Coffield, ${ }^{2} \mathrm{~A}$ Ward, ${ }^{2} \mathrm{~S}$ Gilbert. ${ }^{1}$ Centers for Disease Control and Prevention, Atlanta, GA, United States, ${ }^{2}$ Partnership for Prevention, Washington, DC, United States

In 2011, Partnership for Prevention (Partnership) collaborated with the US Centers for Disease Control and Prevention to develop a domestic National Coalition for Sexual Health (NCSH). The NCSH's stated mission was to normalise sexual health among the general population and to promote sexual health among populations at higher risk. To develop the Coalition's vision, mission, goals, and priorities, Partnership conducted a series of systematic in-depth interviews with key stakeholders and held consultations with experts in the fields of healthcare, communications, sexual violence prevention, public policy, and sexual health education. Key findings included: (1) The need to give meaning to and build acceptance of the concept of "sexual health" to mainstream sexual health among influential sectors (e.g., media) and the general public; (2) Providing national leadership around sexual health will have downstream benefits for a range of stakeholders, including those focusing on a single aspect of sexual health or specific target audiences; (3) There is possible risk to leaving the traditional disease reduction/disaster avoidance framework and initial work should work to obviate this risk; and, (4) There is broad support for the benefits of a sexual health approach (e.g., coordinating and leveraging resources across national partners)

Findings from these interviews and consultations were used to shape the NCSH's foundation and framing, and feedback was again 
sought from these key stakeholders, along with others, to gain consensus and build support for the new Coalition. This iterative process resulted in a Coalition mission, goals, values, expected member roles, and priority areas of focus which represented the breadth of key stakeholder concerns and priorities. These foundational principles will be presented in depth. Within fourteen months of project start-up, 25 organisations have joined the NCSH and are actively participating in its Action Groups. This participatory, consensusbuilding approach could hold promise for other coalition-building efforts.

\section{P5.056 MISSION IS POSSIBLE! THE GERMAN STI-SOCIETY (DSTIG) AS A PACEMAKER FOR SEXUAL HEALTH AND STI- RESEARCH IN GERMANY}

doi:10.1136/sextrans-2013-051184.1100

\begin{abstract}
${ }^{1,2} \mathbf{N}$ H Brockmeyer, ${ }^{3} \mathrm{~V}$ Bremer, ${ }^{4} \mathrm{H}$ Langanke. 'German STI-Society (DSTIG), Bochum, Germany; ${ }^{2}$ Clinic for Dermatology, Venerology and Allergology, Ruhr-Universität Bochum, Bochum, Germany; ${ }^{3}$ German STI-Society (DSTIG), Berlin, Germany; ${ }^{4}$ German STI-Society (DSTIG), Cologne, Germany
\end{abstract}

Background For the last 111 years the "German STI Society - Society for the Promotion of Sexual Health" (DSTIG) has been the biggest medical and social society focusing on sexually transmitted infections (STI), which brings clinicians, therapists, people working in the sexual health sector or in STI counselling together. This interdisciplinary approach makes it unique in the German landscape of medical societies.

Through it's history the DSTIG achieved a lot, even though a peak-number of 10,000 members in the 1920s is not reached yet again: The transformation through the years has been from a mainly clinically-pathologically oriented Dermato-Venerological expert group to an open society, which focuses on the whole range of STI-research and sciences, including sexual health.

Organization \& Projects: The members of the DSTIG do work on specific topics in six sections for example in the field of sexual health, medical guidelines, STI-research and/or the development of STI-training material. Amongst other projects and publications, the DSTIG-sections developed prevention standards and indicators to measure sexual health, and treatment guidelines on gonorrhoea. Comprehensive recommendations for counselling, diagnosis and treatment of STI patients are being developed; guidelines for Chlamydia and Syphilis are under progress.

Goals Between 2010-2012 the number of members increased by $51 \%$, which is an obvious indicator that the interdisciplinary way of the DSTIG is the right direction. Taking over responsibility by focusing on the people living at the "edges" of our society like sexworkers, immigrants, homosexuals etc. is one of the goals of the DSTIG. As well the DSTIG is on the way to become an important player in the development of STI-guidelines, and this not only on national level but Europe-wide. Therefore the expertise of physicians from different medical disciplines and the close cooperation between professionals on different levels of the German health system are necessary for success.

\section{P5.057 DO YOU GYT? EVALUATION OF THE FIRST TWO YEARS OF THE UNITED STATES' NATIONAL GET YOURSELF TESTED CAMPAIGN}

doi:10.1136/sextrans-2013-051184.1101

\footnotetext{
'A Friedman, 'M Habel, 'R Kachur, ${ }^{1} \mathrm{~K}$ Brookmeyer, ${ }^{1} \mathrm{M}$ McFarlane, ${ }^{1} \mathrm{M}$ Hogben, ${ }^{2} \mathrm{M}$ Mishel, ${ }^{2} \mathrm{~S}$ Levine, ${ }^{3} \mathrm{~L}$ Vadnai, ${ }^{2} \mathrm{~L}$ Kantor. ${ }^{1}$ US Centers for Disease Control \& Prevention, Atlanta, GA, United States, ${ }^{2}$ Kaiser Family Foundation, Menlo Park, CA, United States, ${ }^{3}$ MTV Networks, New York, NY, United States, ${ }^{4}$ Planned Parenthood Federation of America, New York, NY, United States
}

Background The National Get Yourself Tested (GYT) Campaign was launched in 2009 to promote STD communication and testing among youth ( $\leq 25$ years) through multimedia platforms, on-theground outreach, and linking youth to free/low-cost STD testing. It is a public-private partnership effort between the U.S. Centers for Disease Control and Prevention (CDC), MTV Networks (MTV), the Henry J. Kaiser Family Foundation, and Planned Parenthood Federation of America, among other partners. This effort sought to evaluate campaign exposure and associations with STD testing and communication among youth during the first two years of implementation.

Methods Media metrics tracked campaign-related television, web and social-media programmes in 2009-10; a national mail-panel consumer survey of youth assessed campaign recall and self-reported changes in STD testing and discussions in 2010; and STD patient data from partner health centres ( $n=9$ affiliate health centres) tracked STD testing in April 2008 (pre-campaign), 2009 and 2010.

Results In its first two years, GYT received $>18$ hours of airtime on MTV; its website received $>1.5$ million views, and its testing locator made nearly 145,000 clinic referrals. Awareness of GYT among teenage respondents $(n=766)$ on a national survey was $18.3 \%$, among whom roughly $1 / 5$ reported having talked about STDs/testing with a family member $(17.5 \%)$ or friend $(21.2 \%)$. Among participating affiliates, there was a $71.0 \%$ increase in patients receiving STD testing in April 2010, compared to April 2008 (at a period when chlamydia testing rates nationally rose by $<10 \%$ ). Increases were most notable among young, low income and minority patients.

Conclusion This data offers encouraging evidence that GYT is reaching and mobilising youth most in need of testing. Reported testing increases in GYT-partner health centres were greater than national-level trends which varied minimally from 2008-2010. Efforts are underway to conduct a national evaluation of the campaign.

\section{P5.058 A REVIEW OF THE LANDSCAPE OF MOBILE-PHONE APPLICATIONS FOR INFORMATION, EDUCATION, DIAGNOSIS, CARE AND SELF-MANAGEMENT OF SEXUALLY TRANSMITTED INFECTIONS (STIS)}

doi:10.1136/sextrans-2013-051184.1102

'V Gkatzidou, ${ }^{1} \mathrm{~K}$ Hone, ${ }^{2} \mathrm{C}$ S Estcourt, ${ }^{3} \mathrm{~S}$ T Sadiq, ${ }^{4} \mathrm{P}$ Sonnenberg. ${ }^{1}$ Brunel University, Uxbridge, UK; ${ }^{2}$ Queen Mary University of London, London, UK; ${ }^{3} S t$. George's University of London, London, UK; ${ }^{4}$ University College London, London, UK

Background Mobile phone applications (apps), which offer a paradigm shift in healthcare, have potential to transform sexually transmitted infection (STI) prevention and management. Currently, few sexual health related apps exist for young people. We reviewed existing sexual health mobile apps to inform the design of apps that could be used in eSTI2: STI self-testing, diagnosis, and self-management linked to internet-based clinical management and support.

Methods Major online app stores for sexual health-related mobile apps were searched, excluding apps without STI-related content, intended exclusively for health care professionals or those not available in English. Eligible apps were downloaded and assessed for user ratings, download rates, interactivity as well as examined for salient content features.

Results Of 1504 matches from the initial search, 40 unique individual apps met the selection criteria (10 for iPhone, 14 for Android, three for Blackberry, three for Windows, 10 multi platform). The three most prevalent features of eligible apps were sexual health and STI awareness information (60\%), testing information (30\%), and risk calculator features (30\%). 11 of the eligible apps (27\%) featured an interactive component and 8 included information for a range of sexual orientations. Sexual health apps were infrequently downloaded (median 100-500 downloads); not highly rated (average 